\title{
Urban morphogenesis analysis based on geohistorical road data
}

\author{
Hanae El Gouj ${ }^{1 *} \mathbb{B}$, Christian Rincón-Acosta $^{2}$ and Claire Lagesse ${ }^{1}$
}

\author{
${ }^{*}$ Correspondence: \\ hanae.el_gouj@univ-fcomte. \\ $\mathrm{fr}$ \\ ${ }^{1}$ Théma, UMR 6049 CNRS, \\ University of Burgundy \\ Franche-Comté, 32 rue \\ Mégevand, 25030 Besançon, \\ France \\ Full list of author information \\ is available at the end of the \\ article
}

\begin{abstract}
Road networks result from a subtle balance between geographical coverage and rapid access to strategic points. An understanding of their structure is fundamental when it comes to evaluating and improving territorial accessibility. This study is designed to provide insight into the progressive structuring of territorial patterns by analyzing the evolution of road networks. Studying road network morphogenesis requires geohistorical data, provided here by historical maps from which earlier road networks can be digitized. A hypergraph is constructed from these networks by combining road segments into "ways" on the basis of a method for defining the continuity of road segments. Next, indicators are computed for these ways based on topological and geometrical features. The road patterns of three cities in the Burgundy Franche-Comte region of France (Dijon, Besançon, and Pontarlier) at three historical periods (the 18th, 19th, and twentieth centuries) are then analyzed. In this manner, their topological features and centrality characteristics can be compared from snapshots at different times and places. The innovative method proposed in this paper helps us to read features of the road patterns accurately and to make simple interpretations. It can be applied to any territory for which data is available. The results highlight the underlying structure of the three cities, reveal information about the history and the functioning of the networks, and give preliminary insights into the morphogenesis of those cities. Prospectively this work aims to identify the mechanisms that drive change in road networks. Detecting stability or variation in indicators over time can help in identifying similar behavior, despite geographic and cultural distances, as well as evolution mechanisms linked to specificities of each city. The study of road network morphogenesis can make a major contribution to understanding how road network structure affects accessibility and mobility.
\end{abstract}

Keywords: Geohistorical data, Road networks, Spatiotemporal database, Urban morphology, Network analysis, Graph theory

\section{Introduction}

In urban theory, cities are usually studied as physical and spatial objects (Peponis et al. 1983). A city is a living structure and the territory in which it is embedded has a complex composition that cannot be considered as a simple medium for practices and activities. Hence the need to deal simultaneously with both mechanism and shape-the city's functioning and its physical environment.

(c) The Author(s) 2022. Open Access This article is licensed under a Creative Commons Attribution 4.0 International License, which permits use, sharing, adaptation, distribution and reproduction in any medium or format, as long as you give appropriate credit to the original author(s) and the source, provide a link to the Creative Commons licence, and indicate if changes were made. The images or other third party material in this article are included in the article's Creative Commons licence, unless indicated otherwise in a credit line to the material. If material is not included in the article's Creative Commons licence and your intended use is not permitted by statutory regulation or exceeds the permitted use, you will need to obtain permission directly from the copyright holder. To view a copy of this licence, visit http:// creativecommons.org/licenses/by/4.0/. 
More recently cities have been characterized by their organized complexity (Batty 2013). Their structure and development can be better understood by viewing cities as systems of networks and flows (Jacobs 2016). Interactions within those networks can explain many aspects of city functions (Mitchell and Rapkin 1954).

Ever since the Bridges of Konigsberg problem, which laid the foundations of graph theory (Euler 1953), it has been tempting to describe cities as graphs. Complex network theories have embraced this approach by representing streets as arcs and their intersections as nodes. By thinking of the city in terms of its road network, significant ties have been identified between the structural characteristics of its road network and a number of functional aspects of the city. For example, research may address the road network structure as it relates to population density (Tang 2003), service location (Peponis et al. 2007), pedestrian flow (Foltête 2007), movement (Hillier 2006; Penn 2003), and spatial configuration (Nes \& Zhaohui 2009; Omer \& Jiang 2008). Road networks, then, have come to be widely used for assessing city structures and functions.

City road networks are closely linked to the workings of the territory in terms of accessibility (Tannier 2020) because roads are a central and structuring component of cities (Perret 2016). Of the three morphological entities that form the city (road networks, land plots, and buildings), road layout proves the most permanent over time. Whereas buildings are destroyed and rebuilt, or plots subdivided or merged, road networks are subject to little change. But despite their resilience (Wang 2015), they still grow and evolve over time. In fact, the organic evolution of a road network results from local growth governed by densification and from new roads triggering the spatial evolution of the urbanization front (Barthelemy 2015). The main changes occur therefore in suburban or interurban areas in the form of the addition or more rarely the removal of road segments. But within the city core, major changes remain few and far between. When those major changes occur, they are often designed as part of a wider urban planning operation; like the Parisian boulevards or the Cerda plan in Barcelona in the nineteenth century.

To better grasp the information conveyed by road morphology, territorial and urban analyses based on road networks are conducted by researchers from various disciplines (e.g., geographers, physicists, anthropologists, historians, architects). These disciplines come together around spatial simulation and statistical characterization to analyze and gain insight into the development of road networks. Such analyses are often based on models describing urban growth (Batty 2009) or transportation and road networks (Ortúzar \& Willumsen, 2011).

Moreover, the morphological approach studies city structure not just by analyzing its global shape but also through the organization of its road network based on its topological relationships (how elements interconnect) (Marshall 2005). Such studies are mainly based on topological patterns (Buhl et al. 2006) to identify universal features in road network structure (Chan et al. 2011; Lämmer et al. 2006b), including scale-invariance (Kalapala et al. 2006).

Nevertheless, only a few authors link road network topology to its historical foundations. For instance, those concepts can be found in Barthelemy et al. (2013) and Masucci et al. (2014), as well as in a recent study analyzing snapshots of multiple urban sites at different growth stages (Jang et al. 2020). Despite all these valuable contributions, the 
mechanisms by which these networks evolve over time remain unclear and their modeling is in its early stages (Courtat et al. 2011b).

Spatial analysis methods and graph theory have proved effective in studying network evolution based on historical data (road networks (Lagesse et al. 2015) or transport networks (Bonin 2016; Raimbault 2018)).

One of the biggest challenges in studying the historical evolution of road networks is the availability of data especially when considering a broad timeframe of city evolution (Jang et al. 2020; Wang et al. 2019). Based on historical data, methodological, scientific, and technical contributions have been made by creating spatiotemporal databases (Perret et al. 2009), classifying and studying the evolution of urban fabrics (Puissant et al. 2011), and simulating urban dynamics (Perret et al. 2010). Another challenge in tracing historical information over time is data matching. As a supplement to those previous contributions, procedures have been developed to allow large-scale reconstruction of past morphological evolution, for instance by modeling spatiotemporal aggregated graphs (Costes 2016; Dumenieu 2015). Those studies propose a global approach to producing spatiotemporal databases from geohistorical sources.

Based on geohistorical data, the connection between road network structure and the historical development of the city can be studied in depth to account for the overall urban structure. Ever since cities first arose, road networks have been an integral part of urban development (Garden 2006). So road network morphology can mirror urban history, given that the structural properties of those networks contribute to the characterization of the urban fabric (Hamaina et al. 2012). In addition, road networks are analyzed and modeled (Bettencourt 2013; Louf \& Barthelemy 2014) in an effort to understand their evolutionary logics (Strano et al. 2012) and their growth mechanisms (Casali \& Heinimann 2019).

Following up on that research and as part of an interdisciplinary approach, the work presented in this paper combines an innovative method of geohistorical data collection, and a method of analysis of road networks illustrated by three French cities all in the Burgundy Franche-Comté region (Dijon, Besançon, and Pontarlier) in three different centuries (18th, 19th, and 20th), to identify their underlying structures over time.

The three cities were chosen by considering their different population sizes, local contexts, and urban structures. Dijon (around 160,000 inhabitants) and Besançon (around 120,000 inhabitants) are the largest urban centers in the region. They concentrate many services at the regional level and are surrounded by rural areas. Pontarlier (around $30,000$ inhabitants $)^{1}$ is a smaller urban agglomeration in a border area with many exchanges with Switzerland. Its economic strengths are farming and tourism based on outdoor activities. All three cities are linked by spatial proximity, by a regional road network, and by significant commuting flows (home-work; home-leisure). These cities have very different construction dynamics, suggesting different growth logics.

A close analysis of their historical road networks can help us to better understand the progressive structuring of the territorial patterns. The objective is to design an original analytical approach that gives preliminary insights into the morphogenesis

${ }^{1}$ French census of 2017. https://www.insee.fr/ 
of the cities studied, and which can be applied to any territory, wherever data is available.

This research suggests that the spatial layout of the road network, which has come down through time without any major modifications to its existing structure, can reveal the territory's past organization. It also suggests that certain structural properties are to be found in all road networks regardless of where and when they were built.

The morphology of the road networks of the three cities is studied on the basis of their topological and geometrical properties. The aim is to understand why those road networks have come to be structured as they are and how their structures have evolved over time. Such analyses involve an interpretation of centralities and densities and help us to trace back various aspects of the historical and geographical contexts of city morphogenesis. In addition, tracing certain roads back in time can help us understand how they have shaped city development.

The remainder of the paper is organized as follows: "Methods" section presents the methods employed. These comprise, first, a method of geohistorical data production to reconstruct historical road networks from historical maps; then, the construction of the vector of analysis, through the construction of hypergraphs of the road networks; thereafter several indicators are presented, based on the topology and geometry of the road networks. "Results" section sets out the results. Structures of the three cities' road networks are highlighted and the evolution of their geometry and topology over time is also investigated. "Discussion and conclusion" section provides considerations about the morpho-historical approach of this work within the research context presented above. And to conclude, perspectives for further research are presented.

\section{Methods}

\section{Data collection}

Studying road network morphogenesis requires geohistorical data. Yet obtaining those data is a time-consuming task. This is because of factors such as the lack of digitized and georeferenced historical maps, and the variation in the characteristics, conservation conditions, and production techniques of historical maps. Moreover, geohistorical data are imperfect by nature due to information gaps, both geographical imprecisions and temporal uncertainties. Accordingly the creation of a geohistorical database presents a real challenge of combining information and ensuring the veracity and consistency of the data. Nevertheless such a database can help us to identify and characterize imprecisions and data redundancies can be reduced (Perret 2016).

The structuring, implementation, and exploitation of geohistorical data can be explored while bearing in mind that data availability might be subject to quantitative and qualitative restrictions. Thus the approach in this section shows how to efficiently extract information from historical maps that are often partial and imperfect data sources. Then the geohistorical database structure shows how it is built to properly organize, store, and exploit data. Finally a method is discussed for collecting geometric data about historical road networks from present-day ones. 


\section{Historical maps as a data source}

Historical maps can be a valuable source as they provide information about the morphological organization of the territory. Reading them, one can identify the main morphological entities forming cities: road networks, buildings, and plots. Some can also be used to identify spatial, geometric, toponymical, and topological information. In France, the existing geohistorical data of road networks is limited to the digitization work on Cassini maps (mid-eighteenth century). ${ }^{2}$ Following up on this idea and by extending the spatial scale of the digitization approach, this research is linked to a scientific project, COV$\mathrm{ADEO}^{3}$ (collection, visualization and analysis of geohistorical road data), that aims to provide road data for the Burgundy Franche-Comté (BFC) region of eastern France over different historical periods (from the Gallo-Roman period to the twentieth century). Our approach is to collect historical maps on which road networks can be identified and then to digitize the geometric information about the corresponding road networks.

To date, 440 maps have been collected, 325 of which have been georeferenced. These maps are from different sources including departmental archives, municipal libraries, and the digital library Gallica (which belongs to the National Library of France).

The maps are georeferenced and organized in a catalog that provides data related to physical contents (i.e., road networks, urban and rural areas) and identifies the presence of cartographic elements (e.g., legend, orientation, title, author, and scale). This process also allows us to record the historical period to which each map belongs and its spatial coverage. All the maps are stored in a catalog on servers at Maison des sciences de l'homme et de l'environnement (MSHE). ${ }^{4}$ Catalog files are arranged hierarchically from national to local levels for efficient searching. Once ancient maps have been collected and georeferenced, a geohistorical database needs to be implemented.

\section{The geohistorical database structure}

The geohistorical database is designed for optimal data storage, easy access, and to avoid data duplication. The database structure (Fig. 1) considers the map as a central component. It ensures detailed metadata collection for each map, and then connects it to the other database tables, such as author, level, period, covered zone, and data coverage. Each map is stored in a specific file recovered from a specific source. It has a defined level, which refers, both to the zone covered by the map (which may be communal, departmental, regional, or national) and to a detail level of the road network represented (undetailed, inexhaustive, detailed, or highly detailed). The level thus refers to the level of precision and coverage of each map allowing a hierarchal classification based on two criteria. Study areas are defined to ensure a fine spatial analysis at an intermediate spatial scale between departments and municipalities. Data coverage represents the

\footnotetext{
${ }^{2}$ Geohistorical data project (started in 2013) directed by Julien PERRET. Collaboration IGN, EHESS, CEA, IFSTTAR, ArScAn, Géographie-Cités, BnF, INRA, LIVE, Théma, Charta SRL, Le Ny conseil, Archives Nationales, geospective, NYPL, Stanford Collaboration with EHESS through two PhD theses Bertrand Dumenieu (2011-2015) and Benoît Costes (2012-2016). Collaboration with Belgrand GEBD (IFSTTAR, IGN, ENPC, UPE)-MEDDE 2011-2015 geohistoricaldata.org.

${ }^{3}$ COVADEO project (2019-2021, headed by C. Lagesse), funded by the Burgundy Franche-Comté region under its program (ANER) for New research team support.

4 "La Maison des sciences de l'homme et de l'environnement" offers a platform of online storage and file sharing services and applications to the Burgundy Franche-Comté scientific community in human, social, and environmental sciences. Data are stored on Franche-Comté University's computer network.
} 


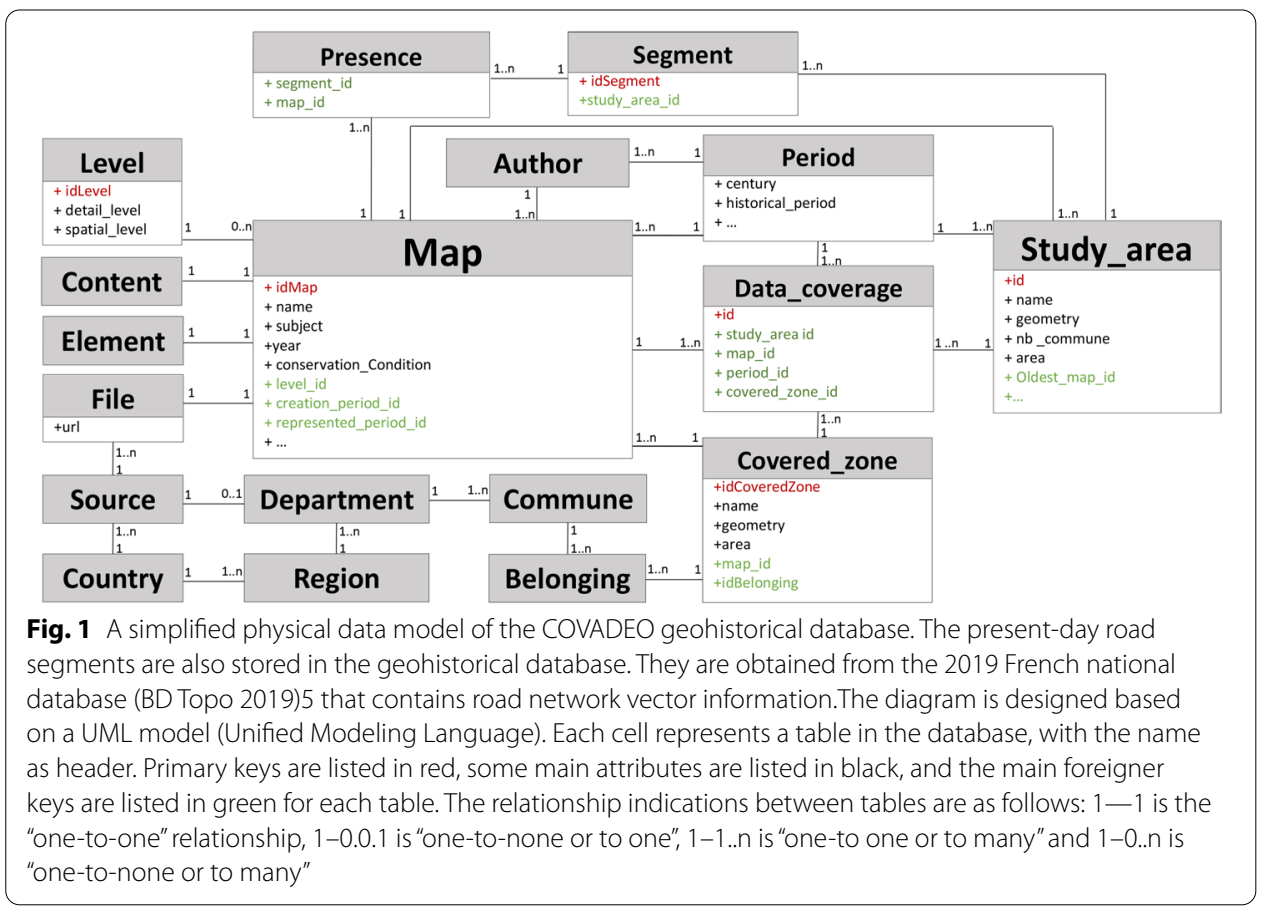

temporal and spatial coverage of data by defining which map represents each study area, the historical period to which it belongs, and the geographic zone represented and covered by the map. These data are also linked hierarchically to the geographic contextcommune, department, region, and country - to which it belongs.

\section{A methodology for collecting geohistorical road network data}

In order to characterize road networks through time, it is essential to acquire the digitized geometry of road segments shown on ancient maps. These geometries should be matched from one map to another for the same territory in order to trace their morphological evolution over time.

The COVADEO research project proposes to digitize the historical road networks based on present-day networks so as to ensure data matching through time. By overlaying the vector layer of the BDTOPO current road network on each historical map, it can be ascertained whether each segment of the extant road network is present, absent, or should be modified on the historical map. Finally road segments requiring adjustment are fixed and the missing ones added (segments shown for the period of the map but no longer existing today). This process is used to fill the "presence" table in the model.

For this paper, the historical road networks of the three cities under study are digitized by this process for the three historical periods. The vector data collected enable us to analyze quantitative and qualitative changes in the historical road network in the three territories over time and to compare their morphogenesis. 

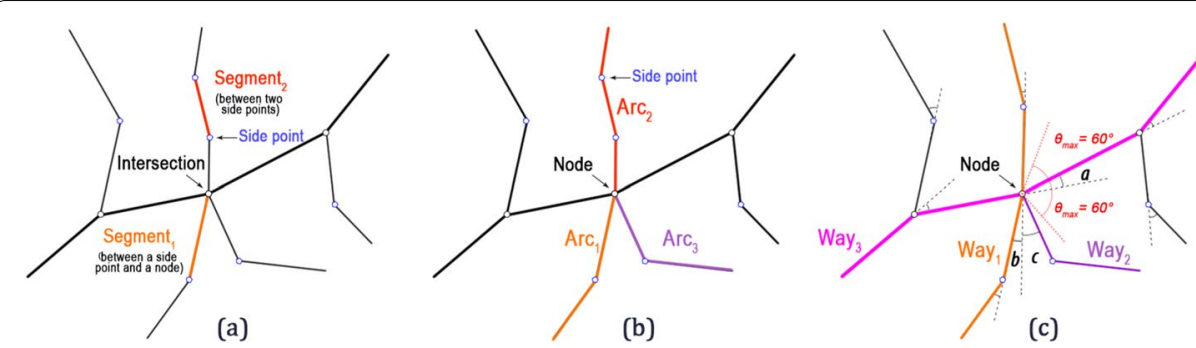

Fig. 2 Construction method of ways on a network sample: a a sample of road segments with side points and intersections; $\mathbf{b}$ construction of a graph with arcs and nodes; $\mathbf{c}$ a hypergraph with ways as an alignment of continuous arcs based on the minimum deviation angle and the chosen threshold $\theta_{\max }=60^{\circ}$, (for example: Way ${ }_{1}$ is constructed based on the fact that the angle $\boldsymbol{b}$ between $\operatorname{Arc}_{1}$ and $\operatorname{Arc}_{2}$ is less than the angle $\boldsymbol{c}$ between $\operatorname{Arc}_{\mathbf{2}}$ and $\operatorname{Arc}_{\mathbf{3}}$.

\section{A hypergraph and network indicators for analyzing road networks}

\section{Building "ways"}

City road networks are based on a sense of continuity to allow movement as initiated by work on space syntax (Hillier et al. 1976), creating an axial map from the road network. This approach consists in keeping the smallest set of longest axial lines covering the space between buildings. It is based on the fact that humans move in a straight line in convex spaces, guided by the depth of their fields of vision (Turner \& Penn, 1999). Following this work, multiple approaches were developed to define road continuity, some based on road toponymy (Jiang \& Claramunt 2004), others on their similar physical or geometric properties (Porta et al. 2006a), and others on a straight-line of street segments (Courtat et al. 2011a, b, c). Based on graph theory, road networks are apprehended with two main types of network representation: primal and dual approaches. The primal approach (Porta et al. 2006c) has the advantage of preserving city geometry insofar as street segments represent arcs and intersections are graph nodes. The dual approach (Porta et al. 2006b) was initially used in spatial syntax (Hillier et al. 1976) by analyzing a dual network formed by axial lines. Thus, axes (aligned streets portions) are represented by nodes and intersections are represented by graph links.

A road network is then usually approximated with segments linking crossing points; and this continuity of road units has to be defined so that their structural properties can be analyzed. By revising the Intersection Continuity Negotiation (ICN) method (Porta et al. 2006a, b, c). Lagesse (2015) developed a quantitative method of grouping the most aligned arcs by connecting road segments based on their angles at a crossing.

Let $\mathrm{G}$ be a normal graph consisting of arcs $A$ (links) and connecting nodes $N$ (intersections), defined as $\mathrm{G}=(N, A)$. Then, by considering the connecting points of degree 2 as side points, only end-points or crossing nodes with 3 or more links are considered as nodes. Between two nodes, groups of segments (linear links) that are connected to each other, form an arc. The arcs are not necessarily straight as they represent a group of segments between end points. At a given node, the first straight segment (taken between the node and the first side point) indicates the angle $\theta$ at which the curved arc connects at the crossing (Fig. 2).

The method in Lagesse et al. (2015) uses a primal approach. It is based on the association of arcs to form larger elements. It thus preserves the graph structure. At a given 
intersection (node), arcs connected by this intersection are paired according to their minimum deviation angle (with a maximum threshold $\theta_{\max }=60^{\circ}$ ). An extended geographical object called the way is built by the iterative combination of arcs. Segments with changes in direction exceeding $60^{\circ}$ are treated as separate units. Way construction is based on local geometry and segment linearity at road crossings, independently of the order in which the network is read. The resulting network is then shown as an unoriented hypergraph composed of a set of nodes and ways $\mathrm{H}=(N, W)$.

The resulting object is multi-scale, ranging from the single arc to the longest way extending over the entire study zone. This last property allows us to make stable computations regardless of the size of the geographical zone (Lagesse et al. 2015).

Ways can be composed of one or several arcs, so the quantitative analysis is broadened from the local scale to the entire city. The multi-scale property of the way ensures robustness to the delineation of the network sample by strongly limiting border effects as long as the network is cut in a coherent manner.

Vector data of road networks may contain some digitization errors, such as slightly displaced connections of segments at intersections. To fix those errors, a tolerance level of $4 \mathrm{~m}$ around arcs is applied. End points of separate segments are taken to be connected if they fall within the defined tolerance. For all these procedures, we used QGIS.org 2021 and Morpheo $^{5}$ (Lagesse 2015).

\section{A morphological characterization applied to ways}

Structural properties of road networks are fundamentally based on continuity, discontinuity, centrality, and proximity (Taylor et al. 1995). City road networks have been extensively studied to quantify their connections and centralities, mainly adopting a dual approach (Barthelemy 2011; Jiang \& Claramunt 2004; Porta et al. 2006b). In this dual approach, the axes become nodes of the graph and intersections between axes are represented by arcs joining the nodes in the dual representation. The work presented in this paper focuses on topological and geometrical indicators (Lagesse 2015) computed on ways. Once ways have been built using a primal approach, metrics are computed on the primal hypergraph $\mathrm{H}=(N, W)$. It is then possible to produce a dual graph $\mathrm{H}^{\prime}=(W, N)$ (Porta et al. 2006b) to compute centrality indicators based on road network topology (Crucitti et al. 2006; Lagesse et al. 2016).

Considering the hypergraph $\mathrm{H}=(N, W)$ as defined above, those indicators are computed. Metrics computed on the primal graph are degree centrality, connectivity, access degree, orthogonality and spacing. Two other centrality indexes can be computed by different criteria on the dual graph: betweenness centrality and closeness centrality.

The degree centrality indicator corresponds to the number of ways $w$ in a hypergraph $\mathrm{H}$ intersected by a reference way $\left(\mathrm{w}_{\text {ref }}\right)($ Eq. 1$)$.

Connectivity is given for a way $w_{r e f}$ by the number of $\operatorname{arcs} a$ it intersects at each of its nodes $n \in w_{r e f}$ (Eq. 2). It differs slightly from its degree in that a way may intersect more arcs than it intersects other ways, depending on the configuration of the

\footnotetext{
$\overline{5}$ Python package and QGIS plugin for the characterization of spatial graphs, allowing ways construction and indicator calculation.
} 


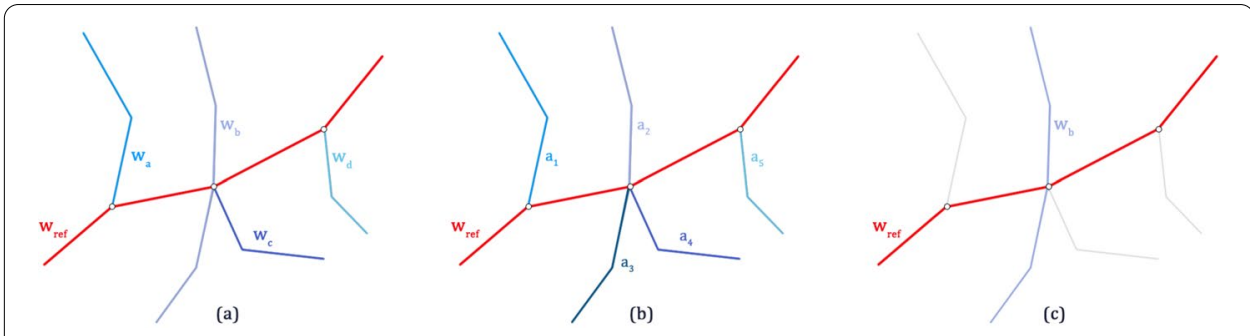

Fig. 3 Diagram illustrating the calculation of the $\mathbf{a}$ degree, $\mathbf{b}$ connectivity, and $\mathbf{c}$ access degree indicators on the same network sample. In this example: a degree is the number of ways that intersect the reference way $w_{\text {refi }}$ i.e., 4 ; in $\mathbf{b}$, connectivity is the number of arcs intersecting $w_{\text {reff }}$ i.e., 5 ; and in $\mathbf{c}$ access degree is the number of ways crossing $W_{\text {ref }}$ in an $\mathrm{X}$-intersection, i.e., 1

junction (as an X-intersection-and so connected to two arcs; or as a T-junctionand so connected to a single arc).

$$
\begin{aligned}
& \operatorname{degree}\left(w_{\text {ref }}\right)=\operatorname{Card}\left(w \in H \mid w \cap w_{\text {ref }}\right) \\
& \text { connectivity }\left(w_{\text {ref }}\right)=\sum_{n \in w_{\text {ref }}} \operatorname{Card}\left(a \mid\left[(n \in a) \wedge\left(a \notin w_{\text {ref }}\right)\right]\right)
\end{aligned}
$$

The access degree indicator is the difference between connectivity and degree. It defines the number of $\mathrm{X}$-intersections as opposed to $\mathrm{T}$-junctions of a reference way $w_{\text {ref }}$ with another way. This indicator highlights ways whose connectivity exceeds their degree (Eq. 3). It is also indicative of accessibility to the territory and how the way is incorporated in the territorial structure. The greater the value of this difference, the more the way intersects its neighborhood centrally and is a part of a continuous structure providing rapid access to the entire network (Fig. 3).

$$
\operatorname{accessDegree}\left(w_{\text {ref }}\right)=\operatorname{connectivity}\left(w_{\text {ref }}\right)-\operatorname{degree}\left(w_{\text {ref }}\right)
$$

Orthogonality characterizes a way according to its angle of connection with its direct neighborhood (Lagesse 2015). This indicator is computed by summing the sine values of the connection's angles between the reference way and the arcs it intersects (always considering the smallest angle at each node $\theta_{a_{i} a_{j}}$ ), and normalizing it by the number of connections: connectivity $\left(\mathrm{w}_{\mathrm{ref}}\right)$ (Eq. 4). Its values vary between 0 and 1 : the closer it is to 1 and the closer the angles are to a right-angle, while the more it tends towards 0 and the more the way connections to the network will be made at a low angle.

Computed locally, for each way, orthogonality reveals particular fabric shapes and helps to identify local and global structures in the road network. It highlights how each way is included in the network, between two extreme cases: ways included in highly meshed structures such as the perfectly regular Manhattan grids; and those with flexible connections such as tree-like slums (Buhl et al. 2006). 


$$
\operatorname{orthogonality}\left(w_{\text {ref }}\right)=\frac{\sum_{n \in w_{\text {ref }}} \sum_{a_{i} \cap n \wedge a_{i} \notin w_{\text {ref }}} \min \left(\sin \left(\theta_{a_{i} a_{j}}\right)\right) /\left(a_{j} \cap n \wedge \in a_{j} \in w_{\text {ref }}\right)}{\operatorname{connectivity}\left(w_{\text {ref }}\right)}
$$

The spacing indicator is also built on geometric criteria. It defines the average distance between two connections by dividing the way length (in meters) by its connectivity (Eq. 5). This is equivalent to an inverse measure of the local linear density of the network. This characterization can be used to identify parts where the road network is concentrated in dense clusters, and those with wider spacing such as the ring roads.

$$
\operatorname{spacing}\left(w_{\text {ref }}\right)=\frac{\text { length }\left(w_{\text {ref }}\right)}{\text { connectivity }\left(w_{\text {ref }}\right)}
$$

After analyzing the network structure at a local level, two other network centralities are computed in order to characterize the global structure. The first centrality derived from the topological distance refers to the number of times one needs to change path or turn to go from one node to all other nodes sequentially. The path between two points with such a minimal distance is also the simplest one, i.e., the shortest to describe with a minimal number of turns in the dual graph representation (Courtat et al. 2011a, b, c).

As applied to ways, closeness centrality represents the topological proximity of the way to the entire network by computing the inverse of the sum of all the topological distances $\left(d_{\text {simple }}\right)$ between ways of the network (Eq. 6). The greater the closeness centrality, the easier access the way will provide to the entire network via simple topological paths.

$$
\operatorname{closeness}\left(w_{\text {ref }}\right)=\frac{1}{\sum_{w \in H} d_{\text {simple }}\left(w, w_{\text {ref }}\right)}
$$

Lastly, betweenness centrality is computed as a measure of centrality based on the shortest paths (Freeman 1977). With respect to ways, betweenness centrality is given by the sum of shortest topological paths between each pair of ways $\left(w_{1}, w_{2}\right)$ that pass through a reference way $\left(w_{\text {ref }}\right)$, divided by the total number of shortest possible paths between these two ways $\left(w_{1}, w_{2}\right)$ (Eq. 7). This indicator quantifies the number of times a way is used along the shortest paths between all pairs of ways of the graph (nodes of the dual graph).

$$
\text { betweenness }\left(w_{\text {ref }}\right)=\sum_{w_{1} \neq w_{2} \neq w_{r e f} \in H} \frac{\sigma_{w_{1} w_{2}}\left(w_{\text {ref }}\right)}{\sigma_{w_{1} w_{2}}}
$$

\section{Static versus dynamic morphological approaches}

By studying the topological metrics presented above, our aim is to show how interpreting the results of the calculated indicators can help highlight the road network structure. Subsequently we consider functional and dynamic aspects of the city to explain the underlying structures. Combining the results of those indicators with information about the urban context helps develop the interpretations. The analyses can allow us to test the 
initial hypothesis about the linkage between road network topology structures and the historical evolution of those structures.

Thus the analysis will be conducted for two separate temporalities. First, characterizing the road network structure at a time $t$, will help reveal the network pattern. Secondly, analysis between $\mathrm{t}-1$ and $\mathrm{t}$ will provide a historical reading of the evolution of the territory and explore the link between the topology of road networks and the historical evolutions of the territory.

We begin by presenting the results of some local indicators (degree, connectivity, orthogonality, and spacing), calculated on the historical road networks of the three cities for the same century in each case. Then we present the results of a local indicator (access degree) and global indicators of centrality (betweenness centrality and closeness centrality) calculated on the historical road networks of each city for the three periods.

In order to compare the results of each indicator for the three cities, all values of each indicator are classified in such a manner that each network has the same classes as the others. Thus, given the same visual signal on the maps, reading the highest values of each indicator provides a meaningful visual comparison. While comparing how the same indicator changes over time in the same city, we also consider the same classes of values for the three periods, as we are not comparing absolute values but ascertaining how ways with the highest or lowest values evolve or remain the same over time. The absolute values of metrics calculated for the three networks are arranged within the same classes, enabling us to compare the hierarchy of those indicators within each network. This means that the assessment of this hierarchy will not be influenced by the number of nodes or ways in each network.

The next section presents the results of those indicators calculated for the historical road networks of the study cases. These results will allow us to analyze the urban structure of each city and provide insight into their evolution over time.

\section{Results}

The work presented in this paper focuses on the analysis of morphological characteristics of road networks. In this section, the historical road networks of three cities of different sizes (Dijon, Besançon, and Pontarlier) are investigated. All three are in the Burgundy Franche-Comté region. Examples are taken from three historical periods ranging from the 18th to the twentieth centuries. The analyses allow us to compare the results of each indicator across the three cities and to look for similarities despite the disparities of the cases studied. They also enable us to monitor the changes in each indicator over time within the same territory. Structural analyses are based on geohistorical and digitized road data for each city and can be used to describe their past organization, to better understand the mechanisms behind their morphogenesis, and to ascertain whether this information can be identified from their road networks. Those analyses are based on the morphology of the network considering shape information only.

While investigating those networks as they evolve over time, it is initially expected that the evolutionary tendencies of centralities (degree, betweenness, and closeness) may be influenced by the size of the network sample (as the spatial coverage varies with the coverage of the historical map). For example, it is easy to imagine that the distributions of 
each indicator value will be greatly influenced by the number of nodes and the number of ways. One can also expect those tendencies to differ from one city to another.

Due to the data, the network coverage at a time $\mathrm{t}$ may be smaller than at $\mathrm{t}-1$, as the spatial coverage of historical maps is often reduced and does not necessarily encompass the total spatial extent of each city. Considering the same spatial coverage over time implies restricting the results to a limited area around the center. Thus it may not be possible to analyze the whole city. In this case the results will not strictly reflect tendencies of the entirety of each city.

Therefore the spatial coverage of each network must be taken into consideration when reading the analysis results. We consider here two special cases. The first is the historical road network of Besançon in 1883 as its spatial coverage is much larger than in 1937. The second one is the historical road network of Pontarlier in 1842, where the covered area is smaller than in 1931.

The following discussion of results focuses on the interpretations of spatial analysis and on the distribution of values for each indicator rather than on network metrics. The analysis results will provide some initial answers and show how evolution logics can be identified independently of the size of the network sample. It will also be shown that some tendencies are common to all three cities and others are specific to each one.

\section{Characterization of the structure across space}

In this study, static morphological analysis is carried out by comparing the results of each indicator for the three cities at the same historical period. First, the three road networks are characterized by the degree of ways (Fig. 4). Analyzing this indicator outlines the most connected and important structures with the highest values (red). They can be identified either as the oldest roads or major traffic roads (avenue, boulevard, departmental road). This indicator allows us to classify the structures according to their capacity to connect different parts of the territory and, by doing so, to define a hierarchy. By considering the urban context of the three different cities, the highest values of degree correspond to the oldest structures, such as "rue de la Liberté" in Dijon, "Grande Rue" in Besançon, and "rue des Salins" in Pontarlier, along with the avenues and the departmental roads passing through each city. It could prove worth tracing the evolution of the oldest roads to assess their involvement in shaping road network morphology, as presented in the next subsection.

From those results we can also read that the layout of the most connected structures differs with the individual dynamics of each city. For Dijon the development of the city is unconstrained and its road network is free to expand in all directions. As we can see from the map, ways with high degree values form a continuous structure. In the case of Besançon, the city core ("La Boucle": the loop) is shaped by the Doubs River, and its development is restrained by topography and hills to the south. So, the city is mainly expanding towards the northeast, north, and southwest. On the map, the underlying structures highlight those dynamics. For Pontarlier natural and topographical constraints mark its morphology, along with its geographical situation as a territory connecting France and Switzerland. So, the most significant underlying structures are those connecting the city to the regional territory (Besançon to the north, Dole and Dijon to the northwest) and those connecting it to Lausanne to the south. We can conclude from 


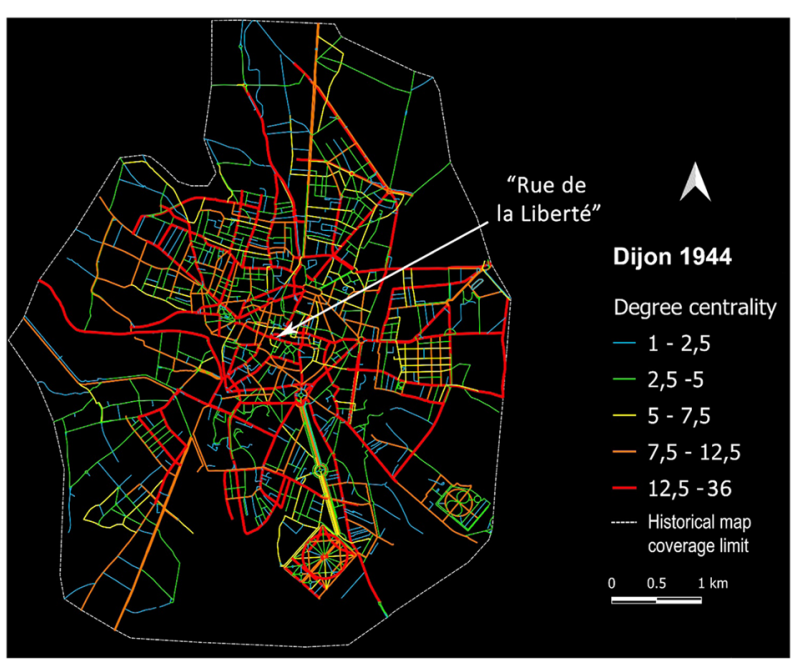

(a)

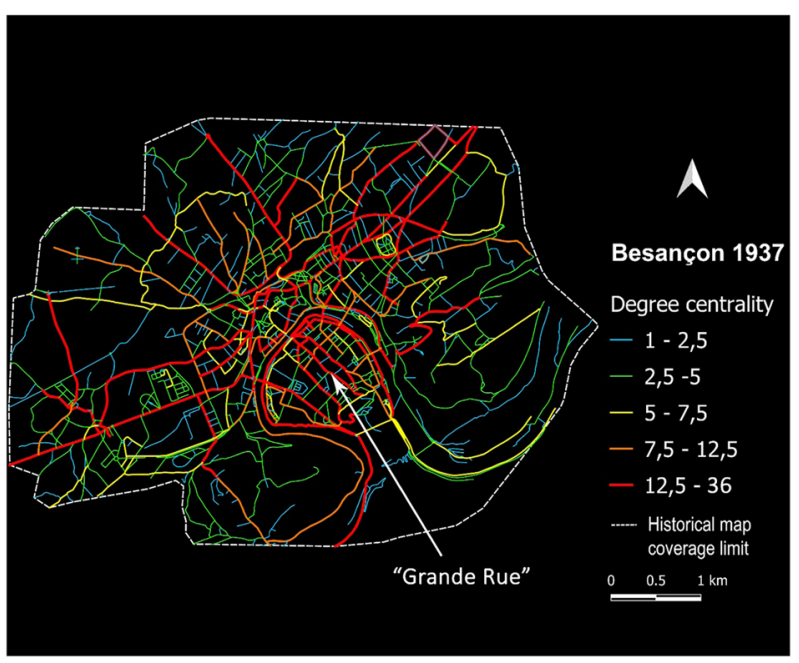

(b)

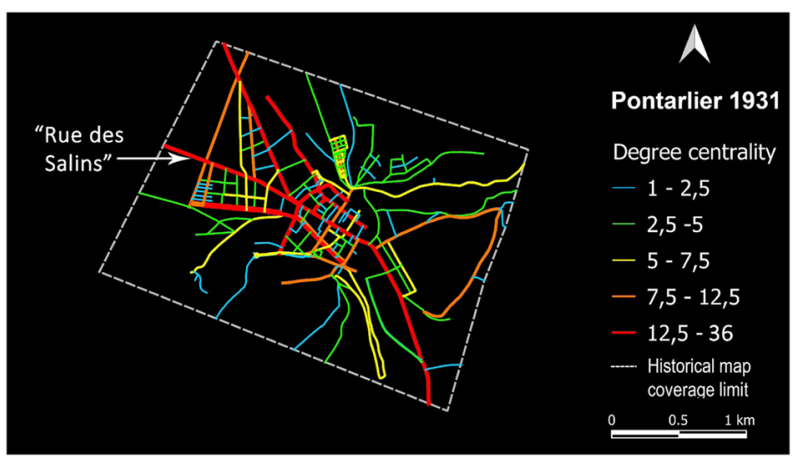

(c)

Fig. 4 Degree centrality indicator calculated on historical road networks of a Dijon in 1944, b Besancon in 1937, and c Pontarlier in 1931 


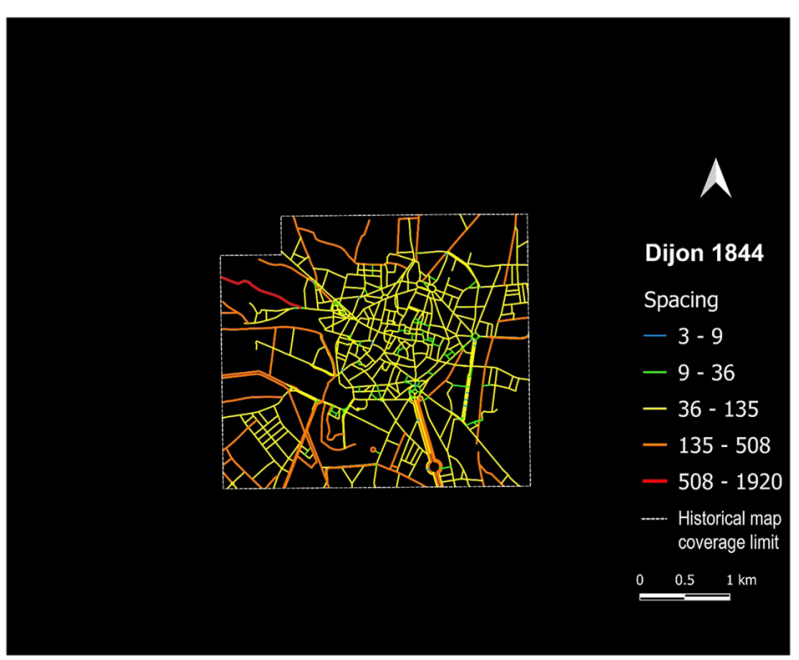

(a)

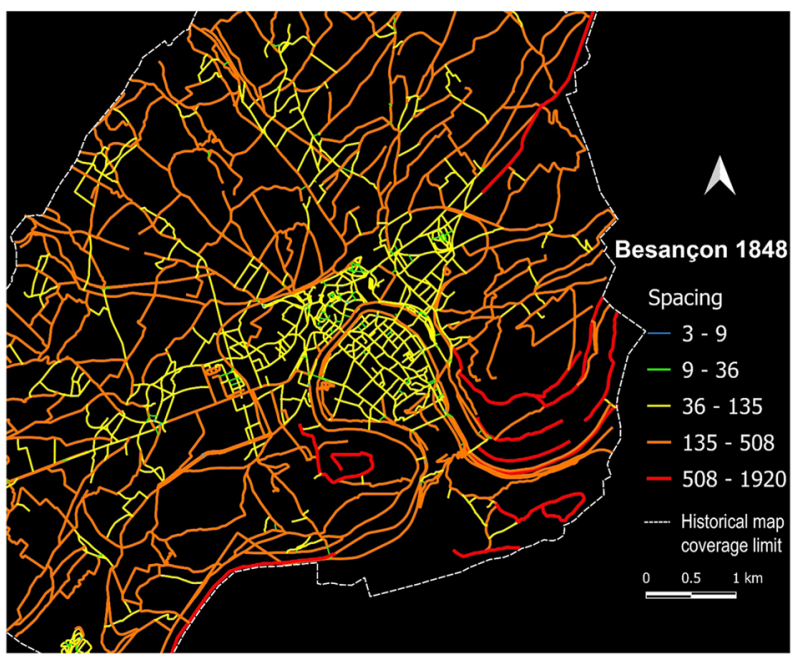

(b)

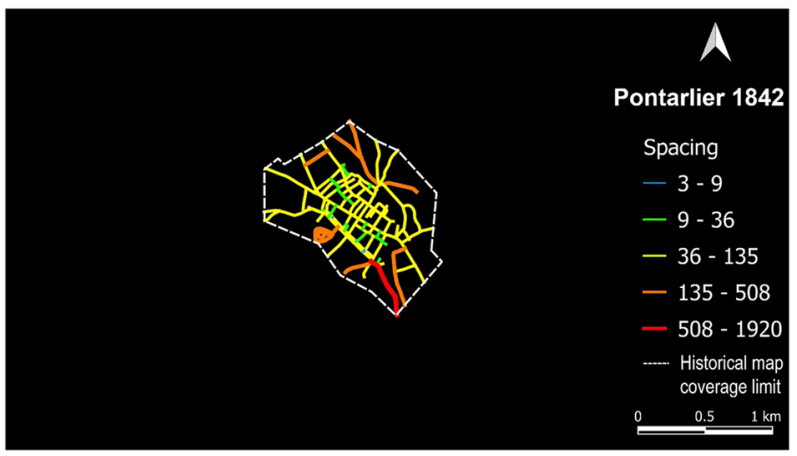

(c)

Fig. 5 Spacing indicator calculated on historical road networks of a Dijon in 1883, b Besancon in 1883, and c Pontarlier in 1842 
this observation that all morphological elements of a territory are closely related to each other and interact decisively. The use of the space also has a significant impact as with Pontarlier where commuting flows impact the polarization of the network. Therefore the degree indicator highlights the main axes of development of cities (accordingly with topological constraints and functional flows).

The spacing indicator calculated for the three cities, despite their different growth stages, shows the lowest to medium values occur in the city core (Fig. 5). This is attributed to the high linear density in the center. The results of this indicator can be interpreted by considering how the topology of ways can reveal travel practices within each area. Short and highly connected ways are most closely spaced and have lower spacing levels (yellow and green in Fig. 5). In the three cities under study they mainly provide local access and facilitate pedestrian movement within the city center. Conversely, the longest, poorly connected ways (orange and red in Fig. 4), have higher spacing levels and can be used for fast transitions between different points. Moreover this indicator may also be correlated to topography, especially for Besançon and Pontarlier where territorial development is shaped by topographical constraints.

Yet linking degree and spacing indicators, even when calculated for different periods, reveals each city's skeleton. It is identified by the city center with the oldest roads (with moderate spacing values in yellow in Fig. 5) and by major thoroughfares supporting territorial connectivity (with the highest values of degree centrality in red in Fig. 4).

Furthermore the orthogonality indicator characterizes each city's structure (Fig. 6). The highest values (red) represent ways with an intersection angle close to $90^{\circ}$, with a mainly gridded network in the city core. Ways with the lowest values (green and blue) are organized in a more tree-like structure. Moderate values (orange) ensure the transition between the two structures, as for the ways connecting the city core to the new emerging network segments on city outskirts. Within each city context, the fast traffic roads have mainly low orthogonality as all the local roads connect to them at low angles so as not to disrupt the traffic flow or generate crossover problems. Roads allowing local access are more likely to be organized in a gridded structure to organize access. This pattern is characteristic of organic cities. This indicator is thus able to highlight the logic of construction of the network (here organic).

Based on a structural analysis of each road network at a time $t$, our main result is that the road network topology can be linked to each city's organization and functioning. And by comparing the same indicator for all three cities for a given historical period, some similarities are highlighted in their urban structure despite their disparities. For example, the degree indicator (Fig. 4) highlighted the main axes on the three networks despite their different topological constraints. Also, the histograms representing orthogonality indicator values (Fig. 6) show similarity in their statistical distribution when calculated on the historical road networks of the three cities, but we can still identify the specificity of Pontarlier's road network as the strongly orthogonal one. This relates to the flat topography in the city core.

\section{Characterization of the structure over time}

To study morphological evolution over time, each indicator is analyzed for the historical road networks of the same city for the three historical periods. This approach helps us 

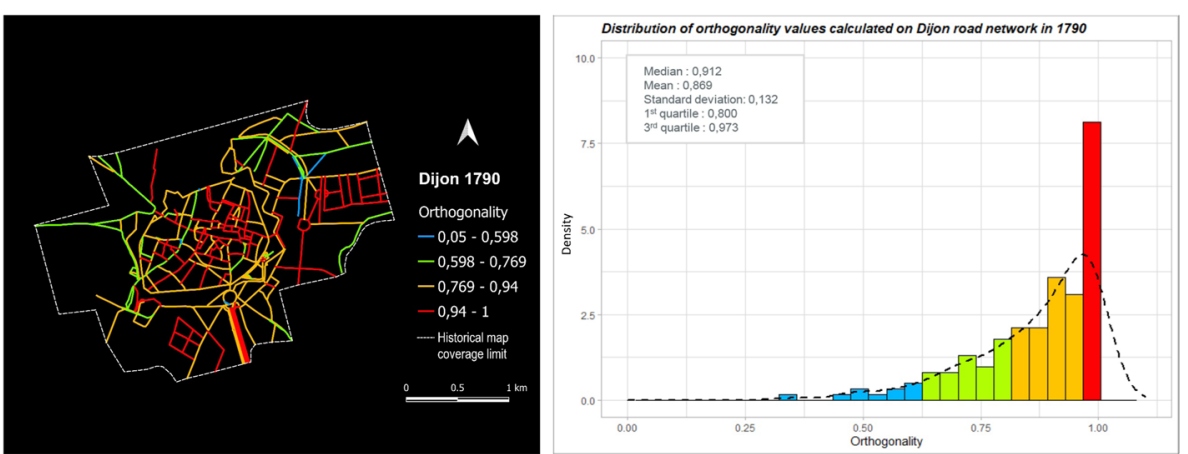

(a)
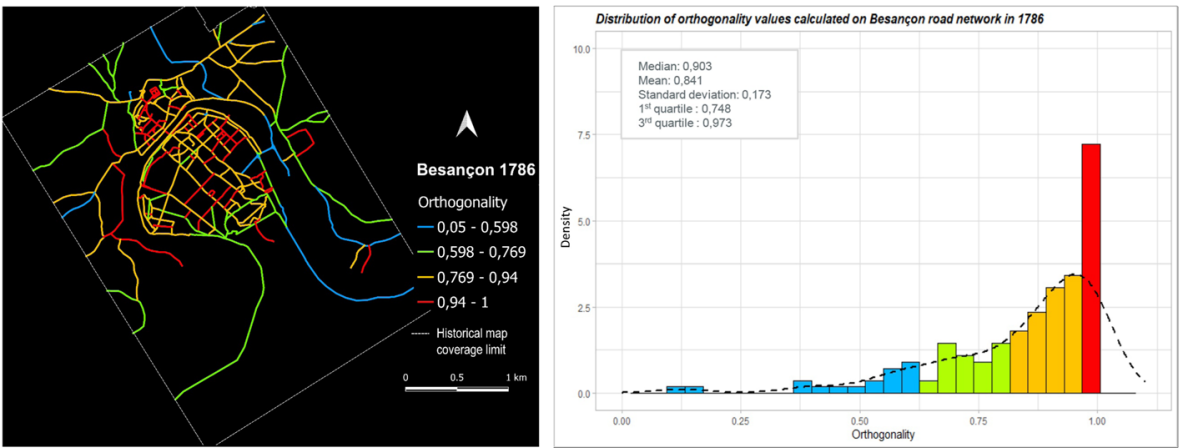

(b)
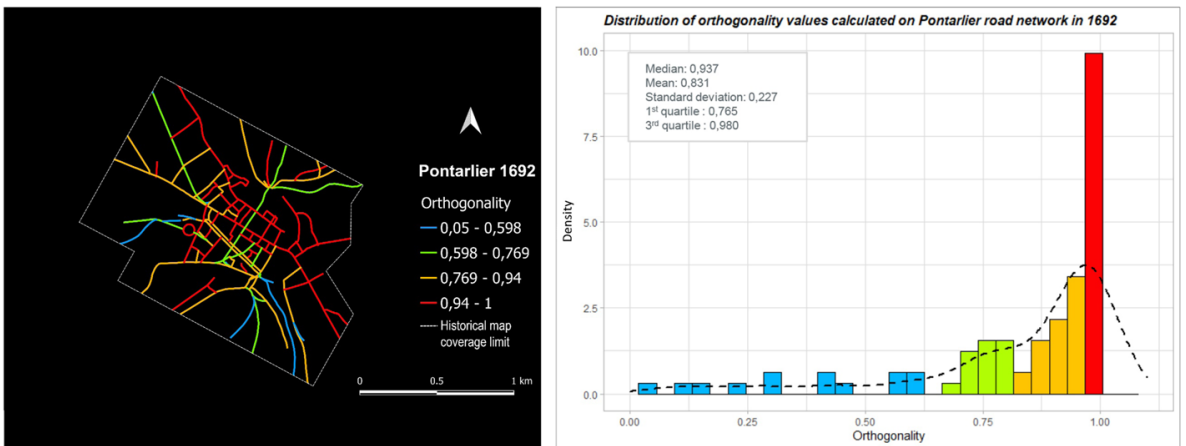

(c)

Fig. 6 Orthogonality indicator calculated for historical road networks of a Dijon in 1790, b Besancon in 1786, and $\mathbf{c}$ Pontarlier in 1692. The histograms represent the distribution of orthogonality values. The dashed black line is the fitting of each histogram with a Gaussian mixture. The bar colors in the histograms indicate the same classification as in the indicator mapping

explore whether road networks convey information related to their growth and use in terms of their layout and their topology. Reading the evolution of road network indicators over time, by linking topology and historical evolution, can provide an understanding of city development. The results presented in this paper compare only one indicator for each city (access degree for Dijon, betweenness centrality for Besançon, and closeness centrality for Pontarlier) at different historical periods.

The choice of indicator for each city depends on what information it highlights and what can be deduced from the city's individual context and dynamics. Dijon-as the largest of the three cities-provides a relevant case study for monitoring the evolution of access from the urban center to the new suburban districts. The access degree 

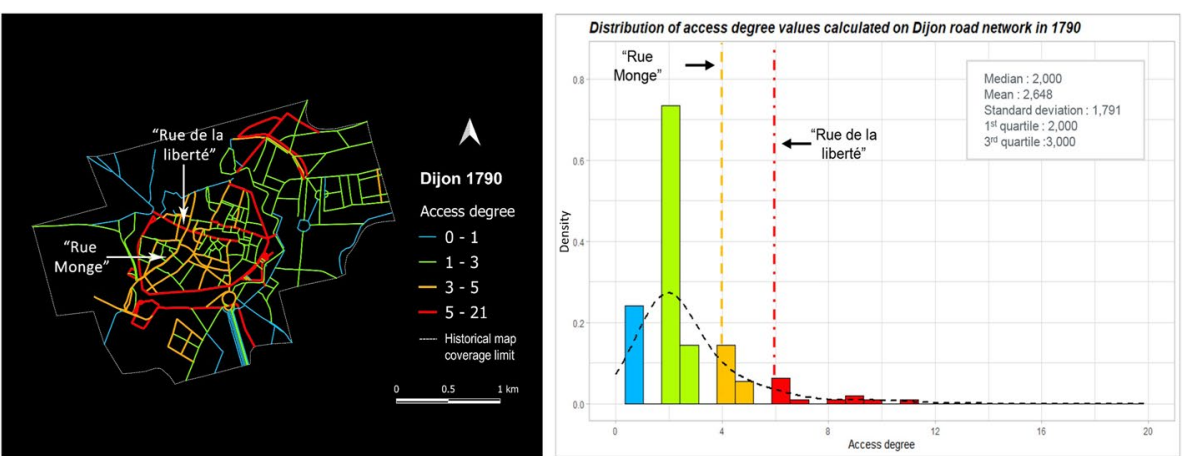

(a)
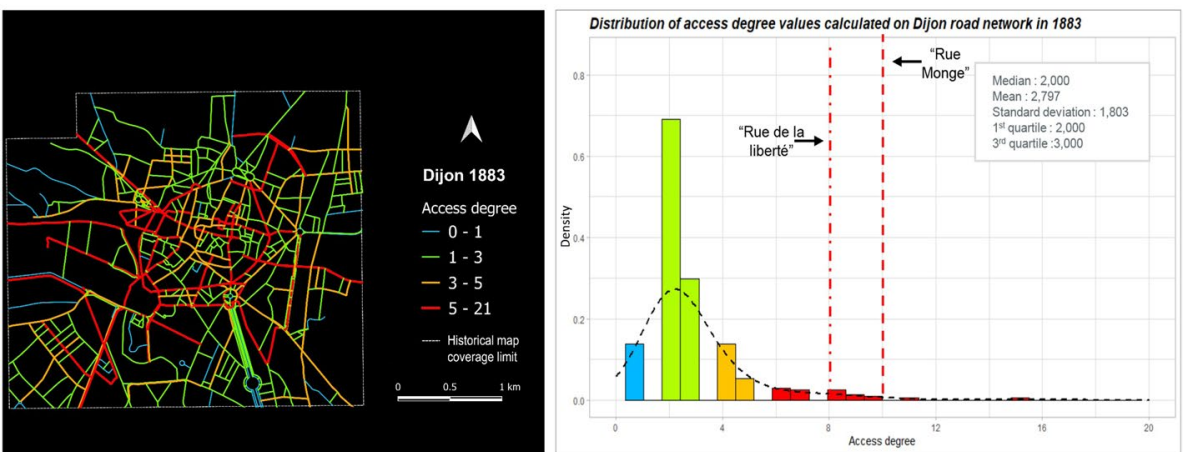

(b)
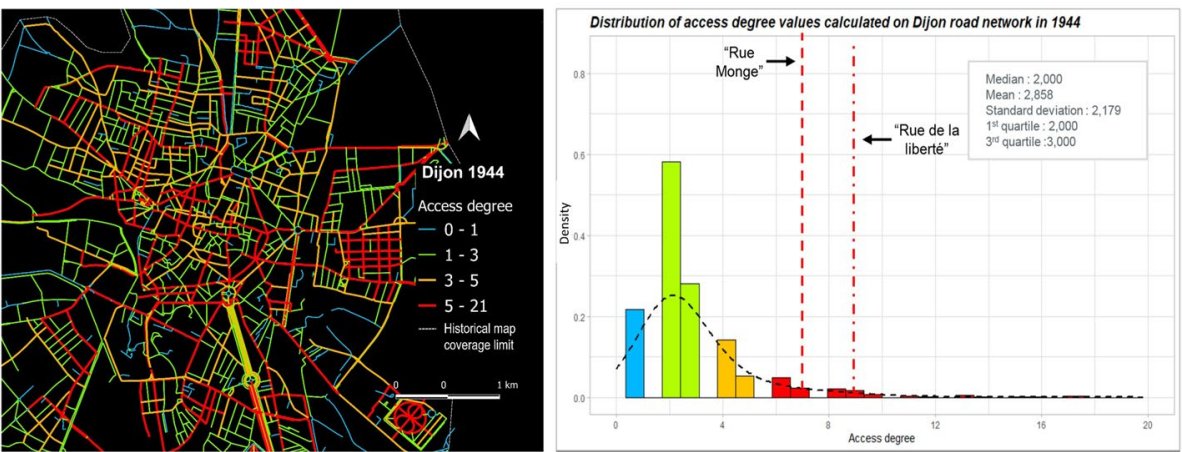

(c)

Fig. 7 Access degree indicator calculated for the historical road network of Dijon in a 1790, b 1883, and c 1944. The histograms represent the distribution of access degree values. The dashed black line is the fitting of each histogram with a Gaussian mixture

indicator underlines this property and was therefore chosen. Besançon-as a city whose urban development has been constrained by its geographical and topographical context-has sprawled in three directions from the center (northeast, northwest and southwest). This particularity has changed the spatial distributions of centralities and the uses of the territory over time, which can be interpreted from the betweenness centrality indicator. Pontarlier-as the smallest city studied-has a network which became denser in the center over time. Tracking the change in closeness centrality will make it easier to assess the link between the age and the topology of the network and to ascertain whether the oldest roads remain the most central. 
First, the access degree computed for Dijon's road networks is shown in Fig. 7. As this indicator defines the number of crossings of a reference way forming intersections and not T-junctions, it highlights the inclusion of the way within the network structure. Roads with the highest access degree values (red and orange in Fig. 7) correspond to the main fast traffic roads in the urban structure, and the old ones which have extended over time. The medium levels represent roads with good access to local areas, and the lowest ones correspond to dead-ends. Ways in the historical city center have a high access degree in the 1790 and 1883 networks, and those values were enhanced in the 1944 network (as for "rue de la Liberté"). This allows us to infer that the city center is the backbone of the territory's development, as its main thoroughfares have largely remained central to accessing the whole city. Between the first two periods, this increase can be explained by the fact that the road network was still densifying within and around the city center. Then, as the city grew over time, the roads in the historical center came to be crossed by new ones that emerged due to urban sprawl and the development of new areas. For example, "rue de la Liberté" became connected to new emerging roads at the limits of the city center, then to departmental roads towards the northeast and northwest, so its access degree evolved over time (as shown in the histograms in Fig. 7). For "rue Monge", the degree of access increased throughout the first two periods then decreased in the 1944 network as this way was not directly connected to the new roads beyond the center.

As time passed and other parts of the city developed, the most important roads in terms of access became those connecting the historical center to the various new urban areas. Those ways are essential for accessing the entire territory. The access degree indicator therefore reveals structure and order (hierarchical organization of road networks).

In Fig. 8, betweenness centrality is calculated for the historical road network of Besançon. The highest betweenness centrality levels correspond to the most frequently used roads, allowing efficient movement within the network (red and orange). Conversely roads with limited use such as dead-ends and footpaths have the lowest values (green and blue). This structure has developed over the years by enhancing the centrality of new urban areas around the historical center of Besançon. Despite urban sprawl, the most active areas of the city in terms of betweenness centrality are still located around the city center and on routes connecting Besançon to the regional territory to the east and west. The increase in the betweenness centrality of ways is mainly linked to the emergence of new segments connected to them to optimize movement within the network. The denser the network becomes, the more movement there is through it, and thus, incrementally, its position is reinforced in the hierarchy of the urban structure. For example, "rue de Vesoul" and "rue de Dole" are connected to the boundary of the historical center, and they are also connected to the regional network (as they both cross the departmental road "D683"). Those roads became frequently used (higher betweenness centrality (Fig. 8)) to access to the city core, to move around the whole city, and to join the regional road network.

For the historical road networks of Pontarlier (Fig. 9), closeness centrality is calculated to analyze the results and their potential meaning within the context of the city's evolution. This metric reflects a gradient of geometric accessibility. High levels of closeness centrality correspond to ways connected to the entire network, via simple 

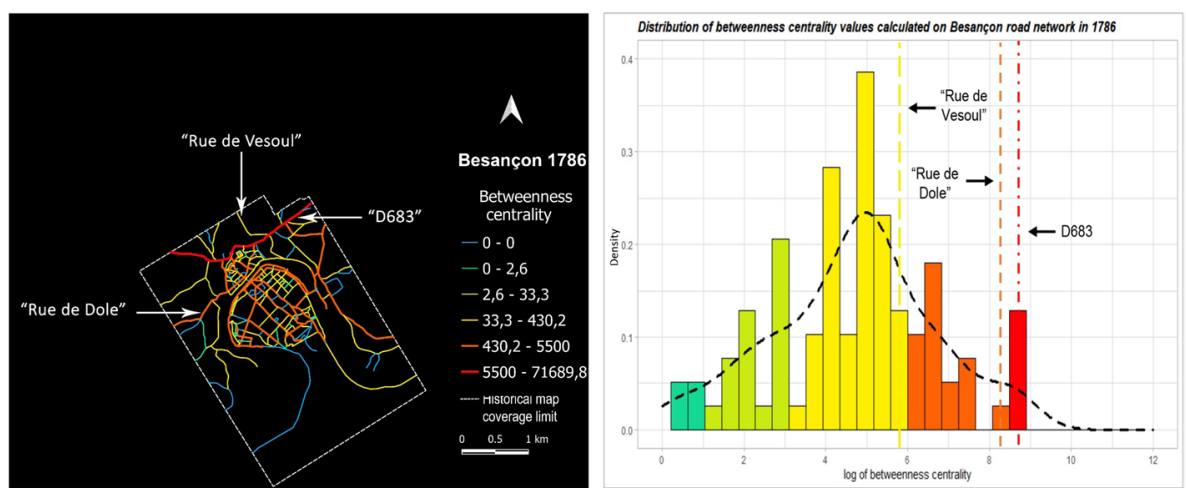

(a)
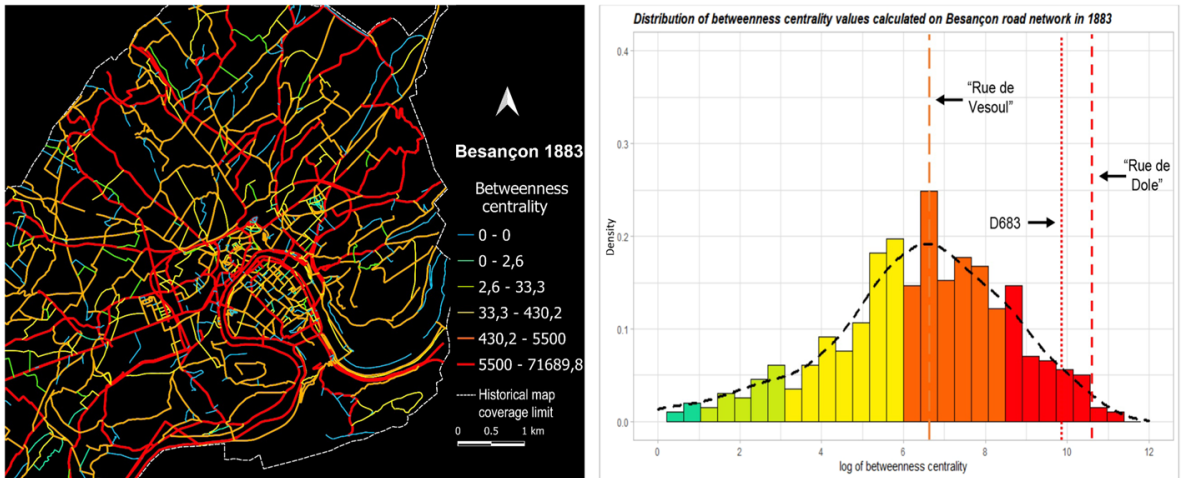

(b)
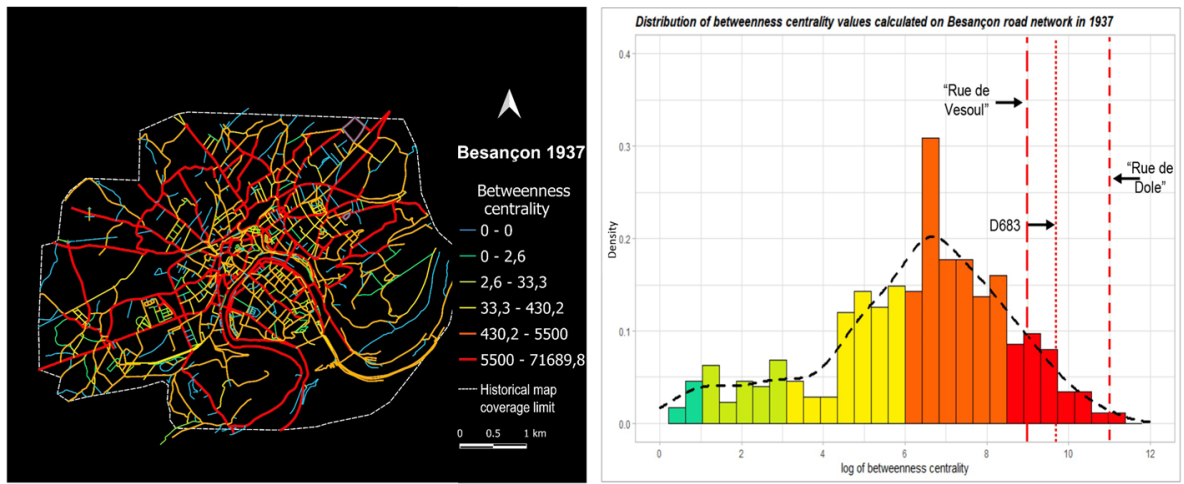

(c)

Fig. 8 Betweenness centrality indicator calculated for the historical road network of Besançon in a 1786, b 1883 , and $\mathbf{c} 1937$. The histograms represent the distribution of the logarithm of way's betweenness centrality. The dashed black line is the fitting of each histogram with a Gaussian mixture

topological paths and ensuring easy access with efficient movement. Reading this indicator (Fig. 9) can give us information about the territory's history. The highest values (red in Figs. 9, 10) correspond to roads in the historical center and the oldest roads connecting Pontarlier to the regional territory, especially to Besançon (to the north), Dole (to the northwest), and Lausanne in Switzerland (to the southeast). The crossing structures highlighted on the map of 1692 are the oldest routes of the city ("rue des Salins" and "rue de la Gare"), their crossing zone is the main center. Over time this initial structure has evolved to shape the city's skeleton. The centrality of the overall structure has remained stable, but following some main roads over time shows the evolution of their 

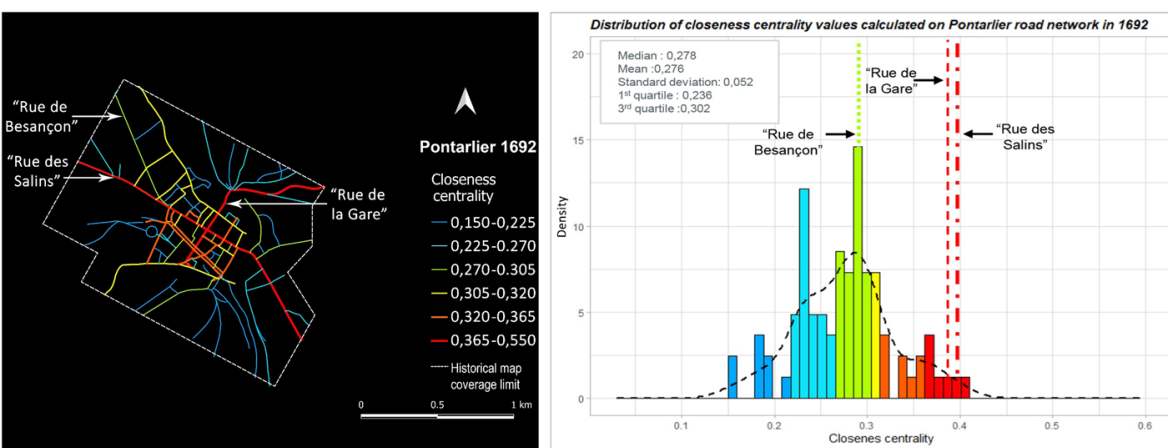

(a)
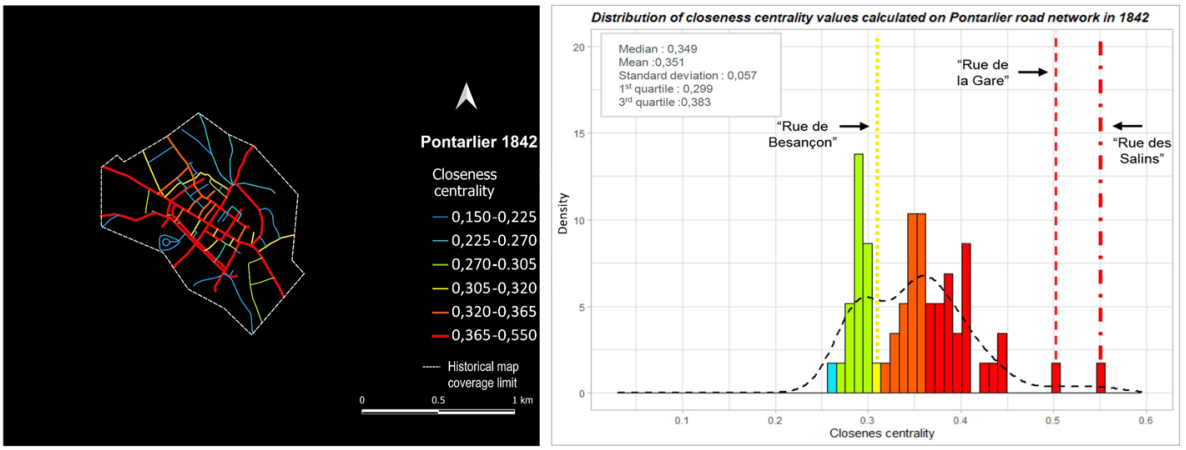

(b)
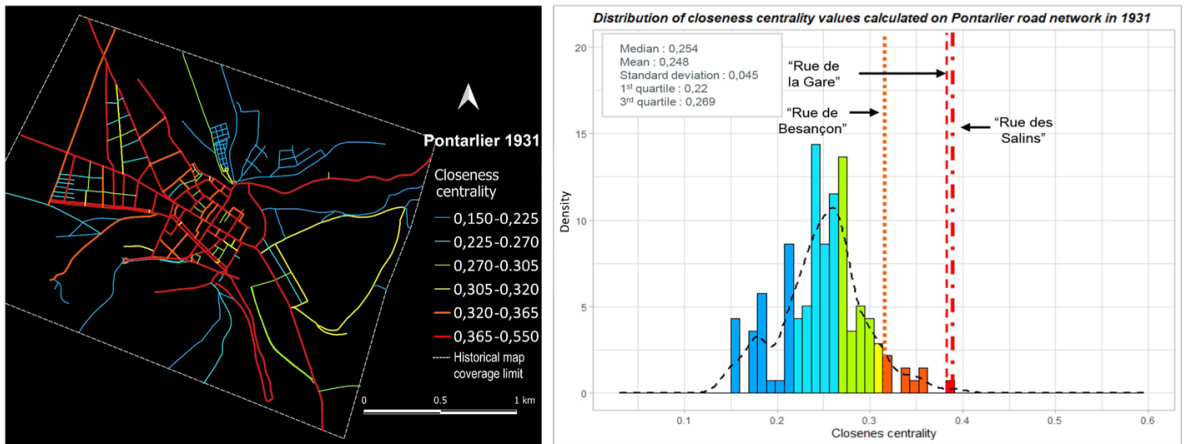

(c)

Fig. 9 Closeness centrality indicator calculated for the historical road network of Pontarlier in a 1692, b 1842, and $\mathbf{c}$ 1931. The histograms represent the frequency distribution of its values. The dashed black line is the fitting of each histogram with a Gaussian mixture

centralities. The highest values highlight roads in the historic center and those connecting the city to the regional territory (for instance "rue de Besançon"). These are fast traffic roads (including departmental roads) connected to the historical center and they also have high values with a strongly meshed accessibility on the main roads.

By tracing the evolution of certain indicators over time for the same city, we can read the changes in centralities of the territory. The above analyses exhibit distinct distributions for each indicator revealing similarities and specificities between the road network structures of the three cities, and within the same city over time. The results provide some initial answers enabling us to advance the initial hypothesis that the topology and layout of road networks convey information about their age and their history. 


\section{Discussion and conclusion}

Representations of cities as graphs have been widely used with complex networks to assess the structure and function of city systems, including road networks (Buhl et al. 2006; Wang et al. 2019). By the same reasoning, reducing the city to its road network as part of a primal or a dual approach (Porta et al. 2006c, 2006b) has proved effective for understanding the structure of urban road networks (Buhl et al. 2006; Kalapala et al. 2006; Strano et al. 2012). Several studies compare the topology of different road networks to assess their structural properties (Cardillo et al. 2006), to study centralities (Courtat et al. 2011a, b, c; Crucitti et al. 2006), and to identify universal features in their structures ( Chan et al. 2010; Reis, 2008; Lämmer et al. 2006a). But only some of that research relates road network topology to the age of the networks in an endeavor to understand their evolution (Barthelemy 2015; Casali \& Heinimann 2019; Masucci et al. 2014). Following this temporal approach some recent research focuses on the evolution of road topology by relating network vulnerability and resilience to network age and geographic region (Jang et al. 2020), or by exploring the correlation between structure and function of the urban road networks in terms of how they have changed over time (Wang et al. 2019).

Considering the limitations of existing studies and of the availability of data on historical road networks, this paper contributes to an emerging literature focused on understanding how road networks are structured and how their structure evolves over time. This work is rooted in complex networks, graph theory, and urban planning frameworks. Road networks are a dynamic subject of study in all these disciplines.

Furthermore road networks are the backbone of cities and they shape urban structure over time. Road networks grow and evolve with the emergence of new road segments densifying or extending the initial network in such a way that their topology shifts or maintains the city centralities and structures. Elementary processes governing the evolution of road networks are explored in Strano et al. (2012) and Barthelemy (2015) highlighting two simple mechanisms: densification as an increase in the local density of roads around existing urban centers; and exploration as the emergence of new roads triggering the spatial evolution of the urbanization front. The spacing and the orthogonality indicators can give us some first insights to track each of these mechanisms. Ways with the highest spacing and lowest orthogonality are closely linked to an exploration process, and ways with the highest orthogonality and lowest spacing are rather the result of a densification process. Assessing the topology of new links between times $t$ and $t_{+1}$ based on comparison of these two indicators can help us highlight these mechanisms.

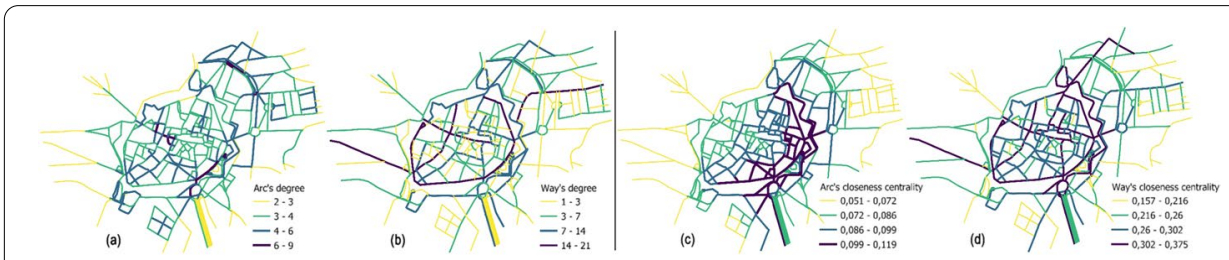

Fig. 10 Degree centrality calculated on $\mathbf{a}$ arcs and $\mathbf{b}$ ways; and closeness centrality calculated on $\mathbf{c}$ arcs and d ways, of the historical road network of Dijon in 1790. Another striking example of the differences of those two computations can be found in Lagesse et al. (2015) 
The empirical identification of such elementary mechanisms suggests the existence of general, simple properties of urbanization.

This work explores those simple properties (with a minimum of information, related to geometry and topology) within the complexity of the road network over different historical periods. The initial analyses show that, by studying the shape and topology of the road network without any additional information, a great deal can be inferred about the city's historical development. This entirely structural analysis provides meaningful characterization from simple interpretations and is consistent with previous findings in Hamaina et al. 2012. Within this work, the network analysis approach adopted can be used to characterize any urban fabric without prior knowledge of the historical context of the city's formation. By combining this analytical approach with a historical approach (by tracing those indicators over time), the simple interpretations of the indicator results can be linked to the relative evolutionary history and the geographic context of each city. This approach therefore provides prima facie evidence of the link between a network's topology and its history and uses, highlighting some spatiotemporal dynamics of road network growth.

Research comparing the topological features of different road networks is based mainly on dual mapping. However, some network metrics, like those based on street length or local geometry, have often been less used in road networks constructed by a dual approach, making them difficult to use for comparative analysis. This paper explores new indicators, which were developed in Lagesse (2015), such as access degree, orthogonality, and spacing, that are newly addressed in the disciplinary field. As we aim to detect similarities in road network topology while maintaining the spatial constraints of local geography for subsequent interpretation, this work combines primal mapped road networks and a dual approach for indicator computation.

An analytical method is then proposed to quantify network evolution by focusing on the layout of way topology and the distribution of each indicator value, and by tracing the evolution of the topology of some major ways over time. Preserving the real geometric representation of those networks enables us to link their spatial layout to the geographic context, and to ensure easier reading of the statistical distributions by visualizing the maps. Furthermore, uses of those ways and functions of the adjacent land can also be explored and this provides valuable information for understanding their evolutionary mechanisms independently of the sample borders.

The analysis of the indicator results calculated on ways has shown that the way is a complex multi-scale object with interesting properties. Constructing ways using only the geometry of the road skeleton and the local information at crossings enables a generic analysis. When computed on ways, network indicators are less time-consuming to compute and simpler to analyze than when arcs are used and they also reveal many features of the road patterns. While centrality indicators computed on arcs are sensitive to the chosen study area and usually indicate its center, they are more significant when calculated on ways as they are multi-scalar (Lagesse et al. 2015). This sensitivity related to the heterogeneous densities of networks is illustrated in Hamaina et al. (2012) and in Lagesse et al. (2015). When computed on ways, centrality metrics reveal the underlying structures from the city center to new emerging roads with a very limited border effect. This robustness is valuable for comparing those networks independently of the network 
sample under study, considering the variation of each historical map cover zone from which road data is extracted.

By adopting a historical approach, our aim is not only to characterize the historical road networks but also, as a next step, to understand how their topology evolves over time. This further work will compare indicators with a two-dimensional analysis to characterize each city's evolutionary trajectory and classify their network patterns. The static analysis opposes similarities and specificities of networks while the differential analysis explores certain aspects of the dynamics. The two are complementary. Based on a structural analysis of each road network at a time $t$, our main result is that the road network structure reflects the key elements of the territory's development and its topography that are highlighted by the indicators. Simplifying the city to its network does not exclude information about its history or its development. Considering simple topological and geometric information is then an effective approach for assessing road network evolution. Those morphological analyses over time based on ways can be used to reconstruct the historical development of the city structure without requiring any additional information. The approach proposed in this work can be applied to any city without any prior knowledge of its urban and geographic context for a primary reading of its development history and its spatial inscription.

In future steps, we will also focus on relating road network topology to historical and territorial evolution, including their capacity to integrate newly emerging segments and their resilience when faced with network disruptions.

Furthermore the spatial and temporal ambition of this research is greater. Because it is very time-consuming to collect digitized geohistorical data on a large temporal and spatial scale, it would be worthwhile organizing the collaborative digitization of historical maps. To do this, the COVADEO project proposes an innovative method of data collection that will allow the study area to be extended for further analysis. The database compiled will be connected to a web platform enabling digitization via crowdsourcing. By iteration, the methodology presented above will help to rebuild the road network geometries of the past from present-day ones, while ensuring data matching. The web database model is already operational. It includes historical data (map metadata) covering the entire region and has provided a basis for our initial analyses.

This serious game will make it possible to digitize the road networks of a large number of maps, which will facilitate quantitative and qualitative analysis of the changing structures of road networks at larger spatial and temporal scales.

Through the serious game, currently under development, anyone will be able to contribute by determining the presence, absence, or necessary modification of each segment of the current road network to be retraced on the historical map. A test version, developed from the Building Inspection Code, NYPL Labs, has been launched online to provide insight into the issues surrounding such means of data production. The final version of the game is planned for the summer of 2022. It is hoped that the data collected will enable a wide range of analyses, thereby providing answers and advancing what is a prominent topic with vast potential for multidisciplinary research.

Indeed, the database model is supposedly capable of storing data about road networks worldwide. Although the initial project concerns the Burgundy Franche-Comté region only, the research work has the potential for development on an international 
scale in the future. Road segment data will then be gathered from the Open Street Map (OSM) database.

By breaching the limitations of data availability, studying and linking road network structure and cities' historical development can be promising. All this information on real road networks is valuable quantitative input for any model of road pattern growth (Barthelemy 2011; Courtat et al. 2010). A morphogenesis model including the evolutionary mechanisms of real networks will be developed in the next stages of this work.

Studying distributions of certain indicators shows great potential for detecting indicator stability or variation in logic over time and for identifying similar behavior despite geographic and cultural distances. In considering the diversity and complexity of cities, their road network structure can exhibit impressive simplicity and universality, as in the distribution of indicator values across the different cities and over time as shown in this paper. This is particularly true of the way structural and dynamic components are organized by scaling laws (Bettencourt 2013).

A better understanding of past morphological transformations will help the different actors engaged in territorial planning to imagine the future evolution of road networks. This could prove a useful way of pushing research and planning to adapt city shapes and territorial organizations for greater commitment to soft mobilities with a view to ensuring sustainable urban development.

\begin{abstract}
Abbreviations
COVADEO: Collection, visualization, and analysis of geo-historical road data; BFC: Burgundy Franche-Comté; IGN: National institute of geographic and forest information; BD TOPO: The second component of the large-scale repository produced by the IGN; TIF: Tagged image file format; GIS: Geographic information system; QGIS: Open-source cross-platform desktop geographic information system (GIS) application; Morpheo: Python package and QGIS plugin for the characterization of spatial graphs (Lagesse, 2015); MSHE: Maison des sciences de l'homme et de l'environnement.
\end{abstract}

\title{
Acknowledgements
}

This research evolved from the work of the Morphocity research team, created as part of a research project MONUMOVI (Numerical Modeling of Urban Morphogenesis) 2012-2016, funded by the French National Research Agency.

\section{Authors' contributions}

HEG and CRA collected maps from the different sources, and created the database. HEG outlined the thematic context, methodology and analysis approach. CRA contributed in producing the data. HEG carried out the analyses that are presented in this paper. CL performed the structure examination of the database, oriented the analysis interpretations, and was the supervisor in writing the manuscript. All authors read and approved the final manuscript.

\section{Funding}

The proposed work is based on the COVADEO project (2019-2021 direction: C. Lagesse), funded by the Burgundy Franche-Comté region, within its funding program (ANER) for New research team support.

\section{Availability of data and materials}

The data used to support the findings of this study are available from the corresponding author upon request.

Declaration

Competing interests

The authors declare that they have no competing interests.

\section{Author details}

${ }^{1}$ Théma, UMR 6049 CNRS, University of Burgundy Franche-Comté, 32 rue Mégevand, 25030 Besançon, France. ${ }^{2}$ University of Franche-Comté, 32 rue Mégevand, 25030 Besançon, France.

Received: 2 March 2021 Accepted: 8 October 2021

Published online: 10 January 2022 


\section{References}

Barthelemy M (2011) Spatial networks. Phys Rep 499(1-3):1-101. https://doi.org/10.1016/j.physrep.2010.11.002

Barthelemy M (2015) Time evolution of road networks. In: Chraibi M, Boltes M, Schadschneider A, Seyfried A (eds) Traffic and granular flow'13. Springer International Publishing, Berlin, pp 317-337

Barthelemy M, Bordin P, Berestycki H, Gribaudi M (2013) Self-organization versus top-down planning in the evolution of a city. Sci Rep 3(1):2153. https://doi.org/10.1038/srep02153

Batty M (2009) Urban modeling. In: Kitchin R, Thrift N (eds) International encyclopedia of human geography. Elsevier, Amsterdam, pp 51-58

Batty M (2013) The new science of cities. MIT Press

Bettencourt LMA (2013) The origins of scaling in cities. Science 340(6139):1438-1441. https://doi.org/10.1126/science. 1235823

Bonin O (2016) Analyse de la croissance de réseaux de transport sur le moyen terme à partir de sources cartographiques: Comment utiliser la carte de Cassini comme source de données ? Flux, No 105(3):5-17

Buhl J, Gautrais J, Reeves N, Solé RV, Valverde S, Kuntz P, Theraulaz G (2006) Topological patterns in street networks ofselforganized urban settlements. Eur Phys J B 49(4):513-522. https://doi.org/10.1140/epjb/e2006-00085-1

Cardillo A, Scellato S, Latora V, Porta S (2006) Structural properties of planar graphs of urban street patterns. Phys Rev E. https://doi.org/10.1103/PhysRevE.73.066107

Casali Y, Heinimann HR (2019) A topological analysis of growth in the Zurich road network. Comput Environ Urban Syst 75:244-253. https://doi.org/10.1016/j.compenvurbsys.2019.01.010

Chan S, Donner R, Lämmer S (2010) Urban street networks as an example for spatial networks with universal geometric features: a case study from Germany.

Chan SHY, Donner RV, Lämmer S (2011) Urban road networks - spatial networks with universal geometric features? A case study on Germany's largest cities. Eur Phys J B 84(4):563-577. https://doi.org/10.1140/epjb/e2011-10889-3

Costes B (2016) Vers la construction d'un référentiel géographique ancien: Un modèle de graphe agrégé pour intégrer, qualifier et analyser des réseaux géohistoriques [PhD Thesis]. Paris Est

Courtat T, Douady S, Gloaguen C (2011) Centrality maps and the analysis of city street networks. In: Proceedings of the 5th international ICST conference on performance evaluation methodologies and tools. Paris, France. https://doi. org/10.4108/icst.valuetools.2011.245740

Courtat T, Gloaguen C, Douady S (2010) Mathematics and morphogenesis of the city, a geometrical approach. 12

Courtat T, Gloaguen C, Douady S (2011a) Hypergraphs and city street networks. Manuscrit

Courtat T, Gloaguen C, Douady S (2011c) Mathematics and morphogenesis of the city: a geometrical approach. Phys Rev E 83(3):036106. https://doi.org/10.1103/PhysRevE.83.036106

Crucitti P, Latora V, Porta S (2006) Centrality measures in spatial networks of urban streets. Phys Rev E 73(3):036125

Dumenieu B (2015) Un système d'information géographique pour le suivi d'objets historiques urbains à travers l'espace et le temps. Thèse soutenue le 4 décembre 2015. L'Atelier du Centre de recherches historiques. Revue électronique du CRH. http://journals.openedition.org/acrh/6932

Euler L (1953) Leonhard Euler and the Koenigsberg bridges. Sci Am 189(1):66-72

Foltête J-C (2007) Quel rôle du réseau de voirie urbaine sur la distribution des flux piétonniers ? Les Cahiers Scientifiques Du Transport 52:27-44

Freeman LC (1977) A set of measures of centrality based on betweenness. Sociometry 40(1):35-41. https://doi.org/10. 2307/3033543

Garden M (2006) Histoire de la rue. Pouvoirs, No 116(1):5-17

Hamaina R, Leduc T, Moreau G (2012) Caractérisation des tissus urbains à partir de l'analyse structurelle des réseaux viaires. Cybergeo Eur J Geogr

Heitor Reis A (2008) Constructal view of the scaling laws of street networks - the dynamics behind geometry. Physica A 387(2-3):617-622. https://doi.org/10.1016/.jphysa.2007.10.003

Hillier B (2006) Studying cities to learn about minds how geometric intuitions shape urban space and make it work.

Hillier B, Leaman A, Stansall P, Bedford M (1976) Space syntax. Environ Plann B Plann Des 3(2):147-185

Jacobs J (2016) The death and life of great American cities. Knopf Doubleday Publishing Group.

Jang GU, Joo JC, Park J (2020) Capturing the signature of topological evolution from the snapshots of road networks. Complexity. https://doi.org/10.1155/2020/8054316

Jiang B, Claramunt C (2004) Topological analysis of urban street networks. Environ Plann B Plann Des 31(1):151-162

Kalapala V, Sanwalani V, Clauset A, Moore C (2006) Scale invariance in road networks. Phys Rev E 73(2):026130. https://doi. org/10.1103/PhysRevE.73.026130

Lagesse C (2015) Lire les lignes de la Ville [Theses, Universite Paris Diderot-Paris VII]. https://halshs.archives-ouvertes.fr/ tel-01245898

Lagesse C, Bonnin P, Bordin P, Douady S (2016) Méthodologie de modélisation et de caractérisation des réseaux spatiaux. Application au réseau viaire de Paris. Flux 3:33-49

Lagesse C, Bordin P, Douady S (2015) A spatial multi-scale object to analyze road networks. Netw Sci 3(1):156-181. https://doi.org/10.1017/nws.2015.4

Lämmer S, Gehlsen B, Helbing D (2006) Scaling laws in the spatial structure of urban road networks. Phys A Stat Mech Appl 363(1):89-95

Lämmer S, Gehlsen B, Helbing D (2006b) Scaling laws in the spatial structure of urban road networks. Physica A 363(1):89-95. https://doi.org/10.1016/.jphysa.2006.01.051

Louf R, Barthelemy M (2014) A typology of street patterns. J R Soc Interface 11(101):20140924. https://doi.org/10.1098/ rsif.2014.0924

Marshall S (2005) Streets and patterns.

Masucci AP, Stanilov K, Batty M (2014) Exploring the evolution of London's street network in the information space: a dual approach. Phys Rev E 89(1):012805. https://doi.org/10.1103/PhysRevE.89.012805

Mitchell RB, Rapkin C (1954) Urban traffic: a function of land use. 
Nes A, Zhaohui S (2009) Network typology, junction typology and spatial configuration and their impacts on street vitality in Singapore

Omer I, Jiang B (2008) Topological qualities of urban streets and the image of the city: a multi-perspective approach

Ortúzar JD, Willumsen LG (2011) Modelling transport. Wiley, New York

Penn A (2003) Space syntax and spatial cognition: or why the axial line? Environ Behav 35(1):30-65. https://doi.org/10. $1177 / 0013916502238864$

Peponis J, Allen DA, French S, Scoppa M, Brown J (2007) Street connectivity and urban density: Spatial measures and their correlation. http://www.Spacesyntaxistanbul.ltu.Edu.Tr/.

Peponis J, Burdett R, Hanson J (1983) Space syntax, a different urban perspective. Archit J 178:47-63

Perret J (2016) Des données spatio-temporelles aux dynamiques urbaines [Habilitation à diriger des recherches]. Université de Paris-Est

Perret J, Curie F, Gaffuri J, Ruas A (2010) A multi-agent system for the simulation of urban dynamics

Perret J, Ruas A, Mas A (2009) Understanding urban dynamics: the use of vector topographic databases and the creation of spatio-temporal databases

Porta S, Crucitti P, Latora V (2006a) Analyse du réseau des voiries urbaines: Une approche directe. Planning 33:705-725

Porta S, Crucitti P, Latora V (2006b) The network analysis of urban streets: a dual approach. Physica A 369(2):853-866

Porta S, Crucitti P, Latora V (2006c) The network analysis of urban streets: a primal approach. Environ Plann B Plann Des 33(5):705-725

Puissant A, Lachiche N, Skupinski G, Braud A, Perret J, Mas A (2011) Classification et évolution des tissus urbains à partir de données vectorielles. Revue Internationale De Géomatique 21:513-532. https://doi.org/10.3166/rig.21.513-532

QGIS.org (2021) QGIS geographic information system. QGIS Association. http://www.qgis.org

Raimbault J (2018) Modeling the co-evolution of cities and networks. https://arxiv.org/abs/1804.09430 [Physics].

Strano E, Nicosia V, Latora V, Porta S, Barthélemy M (2012) Elementary processes governing the evolution of road networks. Sci Rep 2(1):296. https://doi.org/10.1038/srep00296

Tang J (2003) Evaluating the relationship between urban road pattern and population using fractal geometry. University Consortium for Geographic Information Science Summer Assembly, UCGIS, pp 1-13

Tannier C (2020) Effets de la distance et dépendance d'échelles dans les modèles géographiques de villes et de territoires. In: Pumain D (ed.) La modélisation en géographie: Villes et territoires, Iste editions, pp. 59-100. https://hal. archives-ouvertes.fr/hal-02527343

Taylor GD, Harit S, English JR, Whicker G (1995) Hub and spoke networks in truckload trucking: configuration, testing and operational concerns. Logist Transp Rev 31(3):209-238

Wang J (2015) Resilience of self-organised and top-down planned cities-a case study on london and beijing street networks. PLoS ONE 10(12):e0141736. https://doi.org/10.1371/journal.pone.0141736

Wang S, Yu D, Kwan M, Zhou H, Li Y, Miao H (2019) The evolution and growth patterns of the road network in a mediumsized developing city: a historical investigation of Changchun, China, from 1912 to 2017. Sustainability 11(19):1-25

\section{Publisher's Note}

Springer Nature remains neutral with regard to jurisdictional claims in published maps and institutional affiliations.

\section{Submit your manuscript to a SpringerOpen ${ }^{\circ}$ journal and benefit from:}

- Convenient online submission

- Rigorous peer review

- Open access: articles freely available online

- High visibility within the field

- Retaining the copyright to your article

Submit your next manuscript at $\boldsymbol{\nabla}$ springeropen.com 